\title{
El valor pedagógico de la educación artística para la inclusión
}

\author{
Marrero Reyes, Ángela María \\ Universidad de La Laguna, La Laguna, España \\ angela.marrero97@gmail.com
}

«Si se calla el cantor, calla la vida»

-Horacio Guarany

\section{Resumen}

Actualmente, nos encontramos en un momento: social, cultural y económico, en el que priman los conocimientos y habilidades de corte técnico e instrumental, para satisfacer así, las necesidades provenientes del ritmo de vida capitalista que tiene al mundo inmerso. Por tanto, las destrezas de corte subjetivo, como lo son: la música, la pintura, la danza... Es decir, la expresión artística, ha pasado a un segundo plano en el sistema educativo y en la vida cotidiana, si se habla en grandes rasgos, negando así el desarrollo de una parte importante del individuo.

Si se habla del sistema educativo, se puede observar cómo las asignaturas de corte artístico, cada vez tienen menos horas en el calendario lectivo, mientras que las materias como: Lengua o Matemáticas, ocupan la mayor parte del horario, provocando así, que los estudiantes queden privados de poder experimentar e intentar desarrollarse y formarse en estos ámbitos, que son importantes pues contribuyen a que el individuo pueda ser capaz de manifestar sus emociones y sentimientos o de percibir de una manera más fiel el entorno en el que vive, entre muchos otros beneficios que tiene la educación artística en todas sus variantes.

Los conflictos de intereses, las guerras, los asuntos políticos o las cuestiones económicas y sociales, hacen que la parte más humana de las personas vaya deteriorándose, es por ello, que el arte es tan importante; porque es capaz de dar el poder de la expresión sin usar palabras, de hacer pensar, emocionar y reflexionar. Por tanto, que debe tener un espacio en la vida de los estudiantes y de cualquier persona, pues compone una variedad de experiencias emocionantes y enriquecedoras.

Si en las leyes se promulga que el alumnado debe desarrollarse de manera moral e íntegra, no se puede dejar la expresión artística al margen.

\section{Abstract}

Nowadays, we are in a social, cultural and economic moment, where the technical and instrumental knowledge and skills are important and vital for serve the needs of the capitalist world where we all live. Therefore, the subjective skills like: music, painting, dance... That is, the artistic expression has moved to a second place in our educative system and in the everyday life, if we talk in broad stokes, denying the development of an important part of the individual.

If we talk about the educative system, we can see how the artistic subjects have less and less impact in the school calendar, while the subjects like: Language or Mathematics, have more time in the schedule. This causes that the students are deprived of being able to experiment and try to develop in the artistic mood. This area is very beneficial, because contributes the individual to being able to express emotions and to perceive the environment more faithfully, among other positive points.

Conflicts of interest, wars, political affairs or economic and social issues make the human part of the people deteriorate. That is why art is so important; because it is capable of giving the power of expression without using words, of making people think, thrill and meditate. Therefore, it must have a space in the lives of the students and of any person, because it composes a variety of exciting and enriching experiences. If in the educational laws it is promulgated that the students must develop in a moral and integral way, it is not po sible to leave the artistic expression aside.

Palabras clave: Educación artística, expresión, desarrollo, alumnado y emoción.

Keywords: Artistic education, expression, development, students and emotion. 


\section{INTRODUCCIÓN}

La variedad cultural que encontramos hoy en día es muy amplia. Pero también cabe destacar que el afán por etiquetar y establecer límites ha provocado que cada vez más, desconozcamos otras maneras de vida; cuando en realidad, todo está conectado.

Cuando hablamos del concepto «multiculturalidad» hacemos referencia a la convivencia de distintos grupos culturales en un mismo espacio, mientras que el término «interculturalidad» hace alusión a la diversidad como algo enriquecedor, eliminando jerarquías y fomentando el intercambio de experiencias entre sujetos de culturas diversas. Por tanto, a nivel de sociedad, podemos apuntar que el término «multiculturalidad» está siendo entendido de manera equivocada y que, además, no existe la «interculturalidad».

En cuanto al panorama educativo y más concretamente en el ámbito artístico del mismo, podemos observar que se han reducido las horas de las enseñanzas de esta índole (música, artes plásticas...) que son tan necesarias para el desarrollo integral del alumnado. Y, además, en el poco espacio que tienen en el horario lectivo, se produce un monopolio de la cultura europea, provocando así que el alumnado proveniente de otras culturas no se sienta identificado con los contenidos que se exponen $y$, por lo tanto, pueda llegar a sentirse discriminado.

Canarias, debido a su posición geográfica y su historia, es considerada un hervidero cultural, por la gran afluencia de personas provenientes de Latinoamérica y África en su mayoría. Por tanto, y en relación con el párrafo anterior, en los institutos canarios, conviven alumnos de diferente procedencia que muchas veces, no se ven identificados con los discursos que se presentan en los centros.

Por ello, es necesario una remodelación del currículo, en la que aparte de aumentar las horas lectivas en cuanto a enseñanzas artísticas se refiere, garantice una integración cultural para el alumnado, aportando así beneficios como: el sentimiento de pertenencia, el conocimiento de otro tipo de arte y la creación de un contexto intercultural.

\section{MARCO TEÓRICO}

Las enseñanzas de corte artístico han sido, durante la evolución de la educación, las eternas olvidadas en el currículo formativo. Siendo asignaturas menospreciadas, pues priman los conocimientos instrumentalistas.

Pedagógicamente hablando, una educación que no fomente la parte subjetiva de la personalidad es un tipo de educación que lejos de ser eficiente, priva al receptor de información del desarrollo de su potencial artístico y creativo. Intentar evitar el carácter idóneo del arte como base para el proceso de enseñanza-aprendizaje, es dar un paso atrás y renegar un poco más nuestra condición humana. Con la entrada en vigor de la LOMCE en el año 2014, podemos observar cómo las asignaturas: Música, Educación Plástica, Filosofía o Tecnología han pasado de ser troncales y obligatorias a optativas. Provocando así fenómenos como: la finalización de la etapa de Educación Secundaria Obligatoria sin haber asistido a ninguna clase de música o la adquisición del título de Bachillerato sin conocer el «Mito de la caverna» de Platón, o el «contrato social» de Rousseau. Todo proceso educativo tiene que tener una base artística que lo avale y lo fundamente, pues es la única manera de garantizar un desarrollo educativo pleno, sostenible y enriquecedor.

En este momento, padecemos una enorme y devastadora crisis social; no hace falta mirar con lupa para darnos cuenta de que vivimos en una realidad donde convergen muchísimas culturas y patrones de conducta. Y, desgraciadamente, lejos de estar aprovechando esta oportunidad y enriquecer nuestras experiencias vitales, construimos muros que a su vez forman ghettos culturales, sin posibilidad de interacción. Y es aquí donde el arte en toda su esencia juega un papel fundamental, pues aparte de ser el soporte, como se explicó con anterioridad, para un desarrollo pleno e íntegro; es el vehículo de transformación social más potente al que podemos recurrir en estos tiempos tan técnicos e industrializados.

Karl Marx, en Manuscritos económicos y filosóficos (1844) expone: "La realidad esencial de una persona no alienada, consiste en ser capaz de expresar sus potencialidades humanas en su trabajo. La realidad esencial de la persona alienada consiste en no ser capaz de hacerlo porque el trabajo que realiza es una especie de esclavitud. A consecuencia de ello se torna apática. Sus capacidades humanas se vuelven extrañas para ella». 
Si extrapolamos esta idea a la sociedad en la que vivimos, nos damos cuenta de que da igual el lugar de procedencia, el color de piel o la forma del lenguaje que adoptemos. Llegamos a un punto común: Poco a poco, hemos ido perdiendo el sentimiento de fraternidad y de humanidad conforme levantamos murallas de «identidades culturales», alienándonos así, de lo que nos hace verdaderamente iguales: el hecho de ser humanos.

Como seres sociales tenemos la habilidad y, sobretodo, la imperiosa necesidad de interactuar entre nosotros. La capacidad expresiva es la que nos dota para realizar estas acciones, y el desarrollo de ésta va de la mano con el arte. Pues adoptando cualquiera de sus múltiples formas, podemos hablar y expresar nuestros sentimientos sin la necesidad de usar palabras, generando así un impacto más fuerte en un plano social más general.

Es por ello por lo que podemos llegar a llorar al oír una canción, nos quedamos sin habla al estar ante una obra de arte en un museo: El arte tiene el poder de crear en nosotros un sentimiento de pertenencia y de identidad, que tantas veces nos cuesta encontrar por nosotros mismos.

Es por este motivo, que la educación artística en los organismos de educación formal es tan importante. Se ha llegado a un punto en el que este tipo de materias son de carácter optativo, como se comentó con anterioridad, provocando así, que los individuos que quieran formarse, aprender y desarrollarse en estos aspectos tengan que acudir a centros especializados como: escuelas de teatro, conservatorios de música o danza... Y cada vez esto ocurrirá con más frecuencia.

Además, podemos observar que existe un monopolio de la cultura europea en los contenidos que se imparten en los centros; se habla de música haciendo referencia a compositores europeos como Chopin o como Picasso en las artes plásticas, dejando de lado a otros artistas de talla mundial de otras procedencias: africana, latinoamericana... Esto puede desembocar en lo siguiente:

Al encontrarnos en un contexto multicultural, como en el caso de las Islas Canarias, muchos alumnos no se sienten identificados con los discursos y temarios que se imparten, pues son de culturas diversas. Cabe realizar una aclaración, y es que ante este aspecto pueden suceder dos cosas: que poco a poco, comiencen a perder los rasgos distintivos de su cultura y a adoptar rasgos de la cultura dominante o que no se impliquen al máximo en el proceso educativo por no tener un sentirse parte de algo. Esta idea nace de la Teoría de la Reproducción de Bourdieu y Passeron (1970), que expone que la institución escolar es el órgano reproductor de contenidos y a su vez, de desigualdades sociales.

Por tanto, y retomando puntos anteriores, la educación artística debe integrar los contenidos y saberes provenientes de otras culturas, para enriquecer la experiencia escolar del alumnado y fomentar principios y valores morales, éticos y sostenibles, que son tan necesarios en nuestra sociedad actual.

M. ${ }^{a}$ Elena Morató, periodista y crítica de arte española, aparte de defender el arte como motor de cambio social, hace un llamamiento al poder crítico del mismo. Pues el hecho de dar visibilidad a través de cualquier manifestación artística de los problemas que emergen dentro de la sociedad puede fomentar el cambio de conciencia de los individuos ante los obstáculos. En el panorama español, podemos observar como las conocidas popularmente como "canciones revolucionarias» cada vez son menos, y las pocas que encontramos son fruto de cantautores poco conocidos a los que solo se puede acceder a escuchar por medio de internet, con lo cual, se concluye en que la sociedad está regida por el monopolio de la música comercial (la que suena en los medios de comunicación como la radio) que, normalmente, es banal y carente de sentido.

Si nos remontamos al periodo comprendido entre los años 1960 y 1980 y nos trasladamos a Latinoamérica, escenario de múltiples masacres, tragedias e injusticias sociales, observamos como desde: Argentina, Chile, Cuba... nacen una serie de cantores como: Facundo Cabral, Mercedes Sosa, Violeta Parra, Jorge Cafrune, Silvio Rodríguez o Víctor Jara. Estas personas, entre muchísimas otras, se autodenominaban "cantores del pueblo» o "cantantes de protesta», pues en sus canciones denunciaban al poder opresor y a todas las desgracias sociales que acontecían en esa época, dotando a la población de esperanza y sentimiento de lucha por sus derechos. La consecuencia de estos actos revolucionarios fue que muchos de ellos fueran perseguidos y en algunos casos, como Facundo Cabral o Víctor Jara, brutalmente asesinados, con la excusa de que eran un aliento para la población y un soplo de libertad para la misma.

Con esta analogía, quiero destacar que la música (entre otras formas artísticas) es un increíble instrumento removedor de conciencias, que tuvo un importante peso en Latinoamérica en aquel tiempo, y que podría ser una herramienta clave de transformación social en España si se le diera la oportunidad, pero el mundo actual, por desgracia, funciona en base a los intereses políticos y económicos. 
En cuanto al panorama africano, que es más desconocido por la falta de información que tenemos acerca de él, cabe destacar a Femi Kuti, hijo del poderoso artista Fela Kuti, proveniente de Nigeria, en sus discursos y canciones denuncia la situación de desasosiego que vive la sociedad africana por asuntos como: la innegable pobreza, las cuestiones de autonomía e independencia y de la desinformación a nivel mundial sobre este continente. Cabe destacar al pianista sudafricano Abdullah Ibrahim, que a través de su música, combatió la discriminación negra en África y la orquesta guineana Bembeya Jazz que con sus piezas, recuerda a las nuevas generaciones de africanos la miseria y la lucha de sus antepasados.

Para concluir con lo anterior, cabe destacar una frase de Facundo Cabral, cantor argentino, asesinado, como se comentó anteriormente, en el año 2011: "No soy de aquí ni soy de allá, no tengo edad ni porvenir y ser feliz es mi color de identidad», esta gran frase dotada de simbolismo, sirve de nexo con las ideas expuestas anteriormente, en la que se destaca la importancia de derrumbar esas murallas imaginarias que se han construido con los años, separando a personas biológicamente similares pero con diversas características, que no cabe duda, servirían para hacernos más conscientes, sostenibles y plenos. Pues no hay nada que llene más que el conocimiento de otras maneras de percibir la vida o de manifestar la vida cultural.

La educación en este aspecto tiene el papel principal, pues es la base por la que todos tenemos de pasar, y el hecho de luchar para conseguir una escuela limpia, ajena a los intereses políticos y cercana al fomento de la cultura o la fraternidad, es algo por lo que todos los estudiosos de la educación deberíamos unirnos. Pues es de imperiosa necesidad recuperar los valores que representantes de la pedagogía crítica, como Paulo Freire, nos transmitió con «Pedagogía del Oprimido».

\section{AMÉRICA LATINA}

Como se señaló en el marco teórico, América Latina es un vasto espacio geográfico en el que habitan, aproximadamente, 626.000.000 personas. Cabe destacar que la determinación o el concepto «Latinoamérica o América Latina» nace en el siglo XIX con objetivo de delimitar la zona que tiene el latín como lengua madre, es decir, las poblaciones que hablan español y portugués del continente americano. Los países que delimitan esta zona (pueden variar según el estudio) son: Argentina, Bolivia, Brasil, Chile, Colombia, Costa Rica, Cuba, Ecuador, El Salvador, Guatemala, Honduras, México, Nicaragua, Panamá, Paraguay, Puerto Rico, Perú, República Dominicana, Uruguay y Venezuela.

Este territorio, ha sido escenario de innumerables problemáticas sociales e injusticias que golpean constantemente a los habitantes de este. Desde la violencia generalizada, la poca calidad educativa y las diversas crisis económicas. Por otro lado, cabe destacar que la identidad de los habitantes está claramente marcada por las influencias sociales y culturales que han aterrizado en el continente a lo largo de la historia, siendo claramente observables desde el punto de vista artístico.

En cuanto al panorama educativo, según los informes PISA, varios países latinoamericanos como: México, Brasil, Colombia o Costa Rica, entre otros, se encuentran por debajo del promedio establecido por la OCDE. Según el Banco Mundial, América Latina registra un 20\% de población rural, esto influye claramente en la educación, pues en la mayoría de casos, se tiene acceso a la educación pero no suele terminarse la formación básica, pues la necesidad de ingresos condiciona a los niños y niñas a renunciar a su formación para trabajar y colaborar en el hogar. Este aspecto es una clara violación del artículo 26.1 de los Derechos Humanos (1948): «Toda persona tiene derecho a la educación. La educación debe ser gratuita, al menos en lo concerniente a la instrucción elemental y fundamental. La instrucción elemental será obligatoria. La instrucción técnica y profesional habrá de ser generalizada; el acceso a los estudios superiores será igual para todos, en función de los méritos respectivos.»

Según la UNICEF, los modelos educativos vigentes no son eficientes, pues favorecen la exclusión y marginalidad de los jóvenes. 21 millones es la espeluznante cifra de niños y niñas que están fuera del sistema educativo o en riesgo de abandonarlo. Todo esto es contrario al Objetivo de Desarrollo Sostenible para el año 2030 número 4: «Educación de Calidad». Pero también, cabe resaltar las iniciativas educativas en diversos países como: Uruguay con los MOOC o las Escuelas Nuevas en Colombia.

En cuanto al arte, como ocurrió en España, se parte de la base de que hablamos de un lugar donde convivieron muchos grupos étnicos, por lo tanto las manifestaciones artísticas responden a patrones: africanos, españoles, árabes... Como en el caso de la samba (originaria de África) y los famosos puntos cubanos que tienen características comunes con la improvisación ibérica. Si hablamos de artes plásticas 
podemos destacar una infinidad de artistas como: Antonio Segui, Fernando Botero, Frida Kahlo... Que usaban su arte para expresar la belleza incuestionable del continente, denunciar injusticias sociales o dar a conocer sus rasgos más personales. Latinoamérica es el claro ejemplo de riqueza cultural y artística, es un hervidero de: sonidos, texturas, composiciones... Que nos confirma cómo la mezcolanza entre culturas no es objeto de discordia ni de incompatibilidad entre humanos, sino la fórmula para llegar a la manifestación más plena y pura del arte: la chacarera, la samba, el tango, el son cubano, las rancheras, el carnavalito, el realismo mágico, la pintura mural... Son el fruto de la fusión cultural, que sirve de vehículo de denuncia social, de crítica, de identificación personal, de diversión, de pensamiento y sobretodo, de introspección y de migración hacia la pureza de la esencia humana.

\section{3. ÁFRICA}

África, también conocida como "La Cuna de la Vida» y también la gran masacrada y olvidada de la historia. El continente africano está caracterizado por un lado por: los vivos colores, el animismo, los ritmos tribales y las danzas más tradicionales. Por el otro lado, encontramos otra realidad: el hambre, la pobreza extrema, las muertes por desnutrición, gobiernos corruptos, explotación, el tráfico de personas y la apropiación de terrenos, que afectan a los 1.216 miles de millones de habitantes del continente.

El panorama es bastante convulso y cambiante. Cabe resaltar la guerra civil de Somalia, activa desde el año 1991 y que ha dejado sin vida a, aproximadamente, un millón de personas, muertes determinadas además por la sequía y la hambruna, que ponen en peligro la vulnerable vida de estas personas. Una situación similar es la que vive Nigeria, con una violenta guerra comenzada en el año 2002 y que ha provocado unos 1.200 .000 refugiados. Otro suceso a destacar son los secuestros en Nigeria, Níger, Chad y Camerún de mano de Boko Haram, grupo terrorista islámico que ha acabado con la vida de más de 20.000 personas o el conflicto del Sáhara Occidental, donde más de la mitad de la población saharaui vive en campos de refugiados, ocasionado por la ocupación marroquí (1975).

Según la ONG Children International, África es el continente más empobrecido del mundo y los 28 países más pobres de la tierra se encuentran en el mismo. Las condiciones, en muchos casos, son inhumanas, provocando fenómenos como: 3 mil muertos al día (niños y niñas) a causa de la malaria o el hecho de que 589 millones de africanos subsaharianos vivan sin electricidad, entre otras muchas situaciones caracterizadas por la muerte y la desgracia. Pero, el periodismo a nivel mundial con respecto a África está viciado, al igual que la mayoría de los habitantes del planeta, a hacer «pornografía con la miseria africana» como bien afirmó el periodista Xavier Aldekoa, pese a la miseria y las condiciones de vida infrahumanas que vive el continente en muchos países, África es mucho más que eso, es: cultura, tradiciones, música y lucha.

\section{DISCUSIÓN Y CONCLUSIONES}

Como se ha expuesto en los apartados anteriores, podemos comprobar cómo la cultura y el arte proveniente de Latinoamérica y del continente africano pueden dotarnos de una nueva percepción del mundo y del concepto de comunidad. Es por ello, que estos lugares deben empezar a ser considerados como el motor y la raíz del cambio educativo, de esta manera, la fusión entre éstos y la cultura europea dará como fruto una concepción muy diferente de la educación, pues será mucho más completa y real. Por lo tanto, África y Latinoamérica deben ser vistas como escenarios de un nuevo saber hacia el mestizaje cultural.

El individualismo es uno de los grandes problemas de la sociedad actual. No nos preocupamos por lo que pasa a nuestro alrededor mientras no nos afecte a nosotros, fomentando así que cada vez se mire por uno mismo más que como comunidad. Los valores como el respeto o el sentimiento de comunidad se han ido perdiendo en las sociedades actuales, sobretodo en las que pertenecen a países desarrollados; mientras que el sentimiento de unión se conserva en las áreas poblacionales en vías de desarrollo.

En este momento actual, nos encontramos ante una situación de emergencia. Debemos encontrar un punto en el que el arte latinoamericano y africano sirvan de elemento de conexión con el arte europeo, para así poder comenzar a producir arte comunitario, que nos represente a todos por igual y no deje a nadie indiferente. Esta es la manera definitiva para poder poner fin al monopolio artístico 
al que estamos expuestos, creando un arte que defienda lo mestizo, para poder lograr establecer una amalgama de visiones, percepciones, canciones, pinturas, danzas... Que nos hagan sentir más humanos, más hermanos y parte de algo inmortal.

¿Qué se necesita ahora mismo? Pues: cantantes, poetisas, pintores, escultoras, redactoras, músicos, activistas... Gente comprometida a crear algo con lo que podamos sentirnos parte de algo. Porque, tras tantas guerras, individualismo, egoísmo, capitalismo, industrialización, globalización... Ya no se sabe qué es lo auténtico y qué es lo falso, se cree que la meritocracia es la mejor manera de educar a las nuevas generaciones, se encarcelan a raperos por estar en contra de la monarquía, se recortan sueldos y presupuestos en educación, se suprimen asignaturas importantes para el alumnado y su desarrollo.

Las verdades a medias, la supremacía europea, la falta de libertad de expresión, el odio entre personas de distinta procedencia... Entre muchas otras cosas más, son la prueba palpable de que vivimos en un mundo lleno de preguntas y con una sola respuesta: el arte mestizo. Es lo único que podrá salvar a una humanidad inmersa en una dura crisis de identidad.

\section{REFERENCIAS BIBLIOGRÁFICAS}

Asamblea General de la ONU. (1948). «Declaración Universal de los Derechos Humanos» (217 [III] A) Paris. Recuperado de: http://www.ohchr.org/EN/UDHR/Documents/UDHR_Translations/spn.pdf .

Bourdieu, P., Passeron, J. (1970) Teoría de la Reproducción. Editorial Fontamara. Recuperado de: https://socioeducacion. files.wordpress.com/2011/05/bourdieu-pierre-la-reproduccion1.pdf.

Gardner, H. (1987). Arte, mente y cerebro. Una aproximación cognitiva a la creatividad. Ediciones Paidós. Recuperado de: https://mediacionartistica.files.wordpress.com/2012/11/arte- mnente-y-cerebro.pdf.

Zippo, P. (11, abril, 2011). Horacio Guarany - Si se calla el cantor. [archivo de vídeo]. Recuperado de: https://www.youtube. com/watch?v=pmtKpKIE5r0.

Marx, K. (1844). Manuscritos Económicos y Filosóficos. Alianza Editorial. Recuperado de: http://ceiphistorica.com/wp-content/uploads/2016/01/Marx-Karl-Manuscritos-Econom\%C3\%ADa- y-Filosof\%C3\%ADa-Ed.-Alianza.pdf.

Morató, E. (2011). Arte y crítica: Otras realidades, otros objetivos. Nuevos espacios para la reflexión social. Quaderns de la Mediterrànea,5. Recuperado de: http://www.iemed.org/observatori-es/arees-danalisi/arxius-adjunts/qm-15- es/ Arte $\% 20 y \% 20$ critica.pdf.

Palacios, L. (2006). El valor del arte en el proceso educativo. Reencuentro. Análisis de Problemas Universitarios. Recuperado de: http://www.redalyc.org/html/340/34004607/.

Willet, F.(2000). Arte Africano. Ediciones Destino. Recuperado de: http://www.geocities.ws/dchacobo/ArteAfricano.PDF. 